\title{
Thermal Processing of Thermal Coal Under Pressure to Produce Semi-Coke and Thermal Energy
}

\author{
Dmitry A. Loginov, \\ Artem P. Chernykh and Sergey R. Islamov* \\ Branch of Sibniiugleobogashchenie LLC in Krasnoyarsk \\ Krasnoyarsk, Russian Federation
}

Received 05.04.2021, received in revised form 03.05.2021, accepted 21.06.2021

\begin{abstract}
The process of thermal processing of brown coals of grades 1B and 2B under external overpressure of gases in the range of $0-4.0 \mathrm{MPa}$ is investigated. The dependences of the main characteristics of the obtained products - semi-coke and combustible gas-on the pressure are established. The material and energy balances of the process of thermal processing of both coal grades are given.
\end{abstract}

Keywords: combined production, brown coal semi-coke, pressure, thermal treatment, moisture, ash content, yield of volatile matter, strength, water absorption, porosity, heat of combustion.

\section{Термическая переработка энергетического угля}

\section{под давлением с получением полукокса}

\section{и тепловой энергии}

\author{
Д.А. Логинов, А.П. Черных, С.Р. Исламов \\ Филиал ООО «Сибнииулеобогащение» в Красноярске \\ Российская Федераиия, Красноярск
}

\begin{abstract}
Аннотация. Исследован процесс термической переработки бурых углей марок 1Б и 2Б под внешним избыточным давлением газов в диапазоне 0-4,0 МПа. Установлены зависимости основных характеристик получаемых продуктов - полукокса и горючего газа - от давления. Приведены материальные и энергетические балансы процесса термической переработки обеих марок угля.
\end{abstract}

\footnotetext{
(C) Siberian Federal University. All rights reserved

This work is licensed under a Creative Commons Attribution-Non Commercial 4.0 International License (CC BY-NC4.0).

* Corresponding author E-mail address: LoginovDA@suek.ru, ChernykhAP@suek.ru, IslamovSR@suek.ru
} 
Ключевые слова: комбинированное производство, буроугольный полукокс, давление, термообработка, влага, зольность, выход летучих веществ, прочность, водопоглощение, пористость, теплота сгорания.

Цитирование: Логинов, Д.А. Термическая переработка энергетического угля под давлением с получением полукокса и тепловой энергии / Д. А. Логинов, А. П. Черных, С. Р. Исламов // Журн. Сиб. федер. ун-та. Техника и технологии, 2021, 14(4). С. 399-407. DOI: 10.17516/1999-494X-0320

\section{Введение}

Бурые угли являются важнейшей составляющей топливной базы тепло- и электроэнергетики России. На долю бурых углей приходится более половины - 52,4 \% (101,2 млрд т) разведанных запасов страны. Однако из-за нерентабельности транспортировки на дальние расстояния вследствие низкой теплоты сгорания возможности использования бурых углей очень ограничены. Указанная проблема все более обостряется по мере роста тарифов на железнодорожные перевозки угля.

Одним из путей решения проблемы является энерготехнологическая переработка низкосортных бурых углей в высокомаржинальный продукт - полукокс [1] с параллельным производством полезной тепловой энергии. Полукокс применяется в качестве углеродистого восстановителя [2] в металлургических процессах производства ферросплавов, высокотемпературного обжига руд и нерудных материалов, а также в других приложениях, требующих использования твердого топлива с высокой теплотой сгорания [3]. В настоящее время в России внедрены технологии термической переработки бурых углей, разработанные компанией «Сибтермо» $[4,5]$. В технологии «Термококс-С» бурый уголь перерабатывается в шахтном аппарате в плотном слое с обращенным воздушным дутьем при температурах 700-900 ${ }^{\circ} \mathrm{C}$. В технологии «Термококс-КС» термическая переработка угля происходит в модифицированном котельном агрегате. И в том и в другом случае осуществляется комбинированное производство двух энергоносителей: тепловой энергии (горючего газа) и среднетемпературного кокса. Одним из недостатков существующих технологий получения кокса из бурого угля является мелкий размер частиц получаемого продукта, что затрудняет его транспортировку, а при необходимости использования в кусковом виде требует введения дополнительной стадии брикетирования, что неизбежно приводит к удорожанию.

В работе исследован теплотехнологический процесс производства кускового полукокса (торговая марка - ПКВД-1) из бурого угля, который заключается в термообработке исходного угля в реакторе при повышенном давлении. В процессе нагрева угольная матрица размягчается и под воздействием внешнего давления сжимается, в результате чего снижается общий объем пор кусков угля. При этом получается кусковой продукт, обладающий механической прочностью, сопоставимой с прочностью исходного угля, высокой низшей теплотой сгорания, сниженным водопоглощением, высокой реакционной способностью и большим удельным электросопротивлением. Также выполнено сравнение с аналогичным продуктом (ПКВД-2), полученным из угля марки 2Б, исследованным ранее [6].

\section{Описание экспериментальной установки}

Эксперименты проводили на лабораторной установке (рис. 1), представляющей собой реактор из нержавеющей стали 1 , рассчитанный на давление до 5,0 МПа, нагреваемый при 


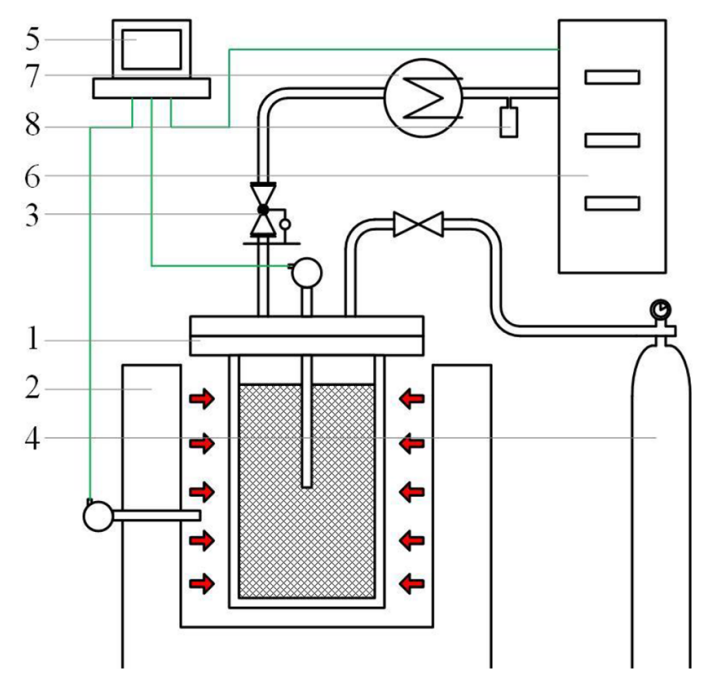

Рис. 1. Схема лабораторной установки: 1 - реактор; 2 - электропечь; 3 - регулятор давления; 4 - газовый баллон; 5 - компьютер; 6 - газоанализатор; 7 - теплообменник; 8 - отводчик

Fig. 1. Laboratory setup diagram: 1 - reactor; 2 - electric furnace; 3 - pressure regulator; 4 - gas cylinder; 5 computer; 6 - gas analyzer; 7 - heat exchanger; 8 - tap

помощи электропечи 2. Реактор оснащен системой автоматического поддержания необходимого давления 3. В начальный момент времени необходимое давление создается при помощи баллона с инертным газом 4. Выходящий из реактора газ направляли на блок газового анализа 6 через теплообменник 7, оснащенный сборником конденсата 8 . Термопары и газоанализатор подключены к компьютеру 5 с возможностью фиксирования показаний в режиме реального времени.

\section{Результаты исследований}

В качестве сырья был взят бурый уголь марки 1Б АО «Приморскуголь». Типичные характеристики использованного в экспериментах угля приведены в табл. 1.

На первом этапе работ при атмосферном давлении была определена зависимость остаточного выхода летучих веществ из получаемого полукокса от температуры нагрева. Работы вели с углем класса крупности 20-25 мм. Засыпку угля помещали реактор, нагревали в электропечи до различных температур. Результаты представлены на рис. 2.

На втором этапе с целью определения влияния режимных параметров процесса на технические характеристики полукокса были выполнены поисковые работы в диапазоне давлений 0,0-4,0 МПа. Процесс получения полукокса включает в себя такие последовательные стадии:

Таблица 1. Технический и элементный состав исходного угля марки 1Б

Table 1. Technical and elemental composition of the initial coal grade 1B

\begin{tabular}{|c|c|c|c|c|c|c|c|c|}
\hline $\mathrm{W}_{\mathrm{t}}^{\mathrm{r}}, \%$ & $\mathrm{~A}^{\mathrm{d}}, \%$ & $\mathrm{~V}^{\text {daf }}, \%$ & $\mathrm{C}^{\text {daf }}, \%$ & $\mathrm{H}^{\text {daf }}, \%$ & $\mathrm{~N}^{\text {daf }}, \%$ & $\mathrm{O}^{\text {daf }} \%$ & $\mathrm{~S}_{\mathrm{t}}^{\mathrm{d}}, \%$ & $\mathrm{Q}_{\mathrm{i}}^{\mathrm{r}}$, МДж/кГ \\
\hline 42,3 & 7,9 & 55,4 & 64,2 & 6,2 & 1,1 & 28,2 & 0,3 & 13,4 \\
\hline
\end{tabular}


загрузка угля в реактор, установка реактора в электропечь, повышение давления внутри реактора инертным газом, нагрев до заданной температуры. Охлаждение и подготовку проб проводили так же, как и на первом этапе работ. Далее было выполнено исследование ряда наиболее важных свойств полученных продуктов.

На рис. 3 и 4 приведены зависимости водопоглощения (ГОСТ 21290-70) ПКВД-1 и ПКВД-2 и объема пор по воде (ГОСТ 17219-71) от давления процесса. Определение прочности на истирание полученных при различном давлении образцов полукокса проводили, как указано в [6]. Результаты представлены на рис. 5.

На основании проведенных исследований был определен оптимальный режим получения полукокса из угля марки 1Б. В табл. 2 даны характеристики оптимальных режимов, свойства полукоксов, состав горючих газов, получаемых в процессе пиролиза угля обеих марок. Материальный и энергетический балансы представлены в табл. 3. Типичные термограммы оптимальных режимов для получения ПКВД-1 и ПКВД-2 отображены на рис. 6.

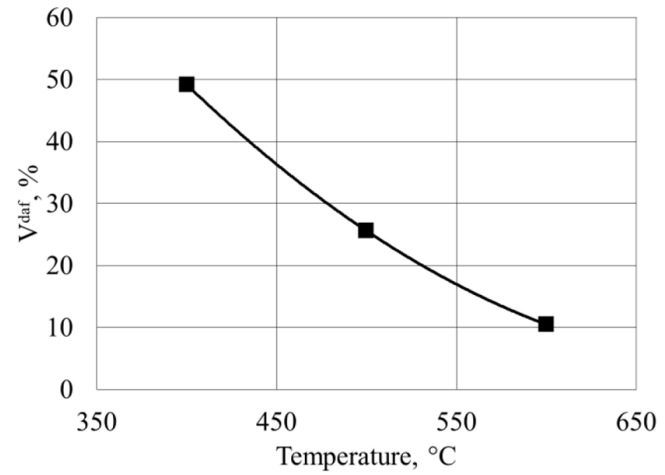

Рис. 2. Зависимость выхода летучих веществ от температуры

Fig. 2. Dependence of the yield of volatile substances on temperature

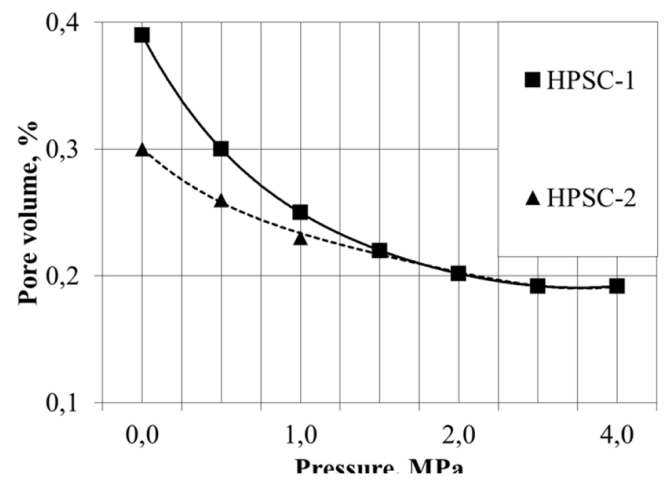

Рис. 4. Зависимость объема пор полукоксов от давления

Fig. 4. Dependence of the pore volume of semi-cokes on the pressure



Рис. 3. Зависимость водопоглощения полукоксов от давления

Fig. 3. Dependence of water absorption of semi-cokes on pressure



Рис. 5. Зависимость прочности М10 полученного продукта от давления

Fig. 5. Dependence of the strength M10 of the resulting product on the pressure 
Таблица 2. Характеристики оптимальных процессов получения ПКВД-1 и ПКВД-2

Table 2. Characteristics of optimal processes for obtaining HPSC-1 and HPSC-2

\begin{tabular}{|c|c|c|}
\hline Параметр & ПКВД-1 & ПКВД-2 \\
\hline Марка угля & $1 Б$ & 25 \\
\hline Температура нагрева, ${ }^{\circ} \mathrm{C}$ & 570 & 570 \\
\hline Избыточное давление, МПа & 2,0 & 3,0 \\
\hline Относительный выход полукокса, \% & 35 & 50 \\
\hline \multicolumn{3}{|l|}{ Технический и элементный анализ полукокса, \% } \\
\hline$W^{r}$ & 3,0 & 1,1 \\
\hline$A^{d}$ & 16,1 & 7,0 \\
\hline$V^{\text {daf }}$ & 13,5 & 11.9 \\
\hline$C^{\text {daf }}$ & 88,3 & 90,7 \\
\hline$H^{\text {daf }}$ & 2,9 & 5,0 \\
\hline$N^{\text {daf }}$ & 1,1 & 1,3 \\
\hline$O^{\text {daf }}$ & 7,2 & 2,8 \\
\hline$S^{d}$ & 0,24 & 0,19 \\
\hline Низшая удельная теплота сгорания, МДж/кг & 26,9 & 31,3 \\
\hline Насыпная плотность, кг/м³ & 500 & 500 \\
\hline Водопоглощение, \% & 6,0 & 6,0 \\
\hline Объем пор по воде, см³/г & 0,19 & 0,19 \\
\hline Прочность $\mathrm{M}_{10}, \%$ & 80 & 80 \\
\hline Удельное электросопротивление, Ом·см & 40,5 & 41,0 \\
\hline Реакционная способность CRI, \% & 90,0 & 89,6 \\
\hline \multicolumn{3}{|l|}{ Средний элементный состав газа, \% } \\
\hline $\mathrm{H}_{2}$ & 3,1 & 1,8 \\
\hline $\mathrm{CO}$ & 11,4 & 10,1 \\
\hline $\mathrm{CO}_{2}$ & 5,5 & 8,3 \\
\hline $\mathrm{CH}_{4}$ & 8,9 & 5,4 \\
\hline$N_{2}$ & 1,2 & 1,4 \\
\hline $\mathrm{H}_{2} \mathrm{O}$ & 69,7 & 72,8 \\
\hline Теплота сгорания газа, МДж/нм & 4,63 & 3,18 \\
\hline
\end{tabular}

\section{Обсуждение результатов}

Уровень выхода летучих веществ полукокса $V^{d a f}$ около 15 \% при использовании в электрометаллургических печах обеспечивает снижение склонности колошникового слоя шихты к спеканию и, как следствие, повышение его газопроницаемости и снижение удельного расхода электроэнергии [7]. Для определения температуры нагрева, требуемой для получения продукта с выходом летучих веществ $V^{d a f}$ не более $15 \%$, поисковые опыты вели в диапазоне температур $400-600{ }^{\circ} \mathrm{C}$. Как видно на рис. 2 , искомый показатель составляет $570{ }^{\circ} \mathrm{C}$, и второй этап исследований производился с нагревом угля до этой температуры.

Водопоглощение ПКВД-1 при повышении давления с 0,0 до 4,0 МПа уменьшается почти в 2,5 раза (с 17 до 7 \%), тогда как для ПКВД-2 наблюдается уменьшение этого показателя вдвое 
Таблица 3. Материальный и энергетический балансы оптимальных процессов получения ПКВД-1 и ПКВД-2

Table 3. Material and energy balances of optimal processes for obtaining HPSC-1 and HPSC-2

\begin{tabular}{|c|c|c|c|c|}
\hline Наименование & \multicolumn{2}{|c|}{ ПКВД-1 } & \multicolumn{2}{|c|}{ ПКВД-2 } \\
\hline \multicolumn{5}{|c|}{ Материальный баланс } \\
\hline & кг & $\%$ & кг & $\%$ \\
\hline \multicolumn{5}{|l|}{ Приход } \\
\hline Уголь & 1000 & 100,0 & 1000 & 100,0 \\
\hline \multicolumn{5}{|l|}{ Расход } \\
\hline Термококс & 350 & 35,0 & 500 & 50,0 \\
\hline Газ & 650 & 65,0 & 500 & 50,0 \\
\hline Итого & 1000 & 100,0 & 1000 & 100,0 \\
\hline \multicolumn{5}{|c|}{ Энергетический баланс } \\
\hline & ГДж & $\%$ & ГДж & $\%$ \\
\hline \multicolumn{5}{|l|}{ Приход } \\
\hline Теплота сгорания угля & 13,4 & 89,6 & 17,59 & 92,5 \\
\hline Теплоподвод для нагрева угля & 1,55 & 10,4 & 1,42 & 7,5 \\
\hline Итого & 14,95 & 100,0 & 19,01 & 100,0 \\
\hline \multicolumn{5}{|l|}{ Расход } \\
\hline Теплота сгорания кокса & 9,43 & 63,0 & 15,66 & 82,4 \\
\hline Тепловая энергия от сжигания газа, из нее: & 4,56 & 30,6 & 2,47 & 13,0 \\
\hline на нагрев угля & 1,55 & 10,4 & 1,42 & 7,5 \\
\hline для реализации & 3,01 & 20,2 & 1,05 & 5,5 \\
\hline Теплопотери & 0,96 & 6,4 & 0,88 & 4,6 \\
\hline Итого & 14,95 & 100,0 & 19,01 & 100,0 \\
\hline
\end{tabular}

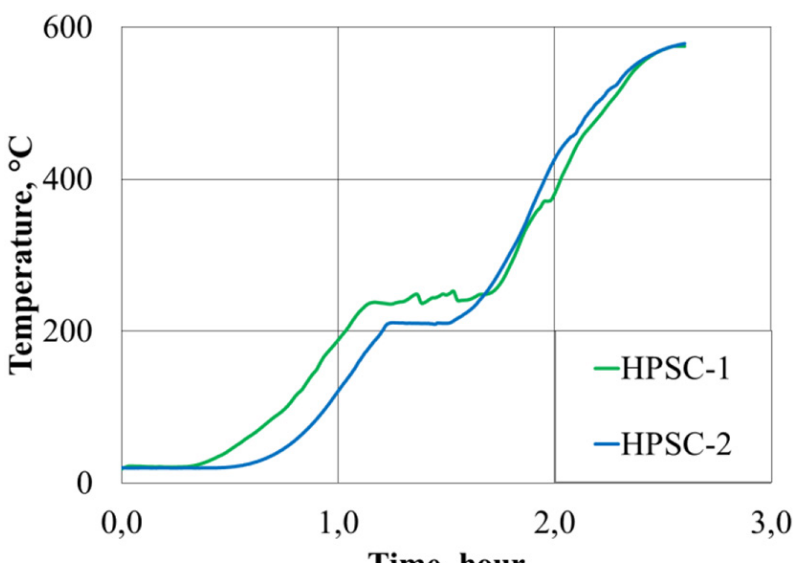

Time, hour

Рис. 6. Типичная термограмма оптимальных режимов процесса получения ПКВД-1 и ПКВД-2

Fig. 6. A typical thermogram of the optimal modes of the process of obtaining HPSC-1 and HPSC-2 
(с 12 до 6 \%). При этом для обоих продуктов резкое снижение водопоглощения происходит в диапазоне давлений от 0,0 до 1,5 МПа, после чего практически не изменяется.

Аналогичная зависимость наблюдается и для общего объема пор полукоксов. Увеличение внешнего давления позволяет достичь снижения общего объема пор вдвое (с 0,37 до 0,19 cм $3 /$ г) для ПКВД-1 и полуторакратного снижения (с 0,3 до 0,19 см³/г) для ПКВД-2.

Исследования показали, что относительный выход и насыпная плотность ПКВД-1 не зависят от давления процесса. При этом повышенное содержание влаги и летучих веществ в угле марки $1 Б$ приводит к снижению относительного выхода полукокса при одной и той же насыпной плотности. Относительный выход ПКВД-1 составляет 35 \% от массы угля, ПКВД-2-50 \%. Значение насыпной плотности полукоксов из обеих марок угля равно $500 \mathrm{\kappa г} / \mathrm{M}^{3}$.

На рис. 4 видно, что ПКВД-1 в диапазоне давлений до 2,0 МПа имеет заметно более низкую прочность, чем ПКВД-2, однако при повышении давления до 3,0 МПа показатели прочности обоих полукоксов практически совпадают и при дальнейшем увеличении давления почти не возрастают.

Горизонтальный участок термограммы на рис. 6 соответствует температурам испарения влаги из угля. Причем при термообработке угля 1Б она на $30{ }^{\circ} \mathrm{C}$ выше, чем для бурого угля, так как процесс проводится при более высоком давлении.

В качестве оптимального режима получения ПКВД-1 был выбран режим со следующими характеристиками: температура нагрева засыпки $-570{ }^{\circ} \mathrm{C}$, избыточное давление процесса $-3,0$ МПа. При указанных параметрах удельная теплота сгорания получаемого горючего газа составляет 4,16 МДж/нм³ ${ }^{3}$ что позволяет сжигать его в топках энергетических котлов без применения дополнительного «подсветочного» топлива.

Организовать непрерывно работающее предприятие комбинированного получения тепловой энергии и углеродистого восстановителя возможно путем установки нескольких реакторов циклического действия. В этом случае из нескольких реакторов, находящихся в различных стадиях нагрева угля, выходит горючий газ усредненного состава. Часть этого газа сжигается в камерной топке теплогенератора для получения высокотемпературных дымовых газов с целью дальнейшего нагрева других реакторов. Оставшаяся часть утилизируется в энергетических котлах для получения полезной тепловой энергии (горячей воды или пара), что позволяет получить дополнительную экономическую выгоду.

\section{Выводы}

В результате исследования процесса полукоксования бурого угля марки 1Б под внешним избыточным давлением газов были установлены зависимости характеристик получаемого продукта от давления и температуры. Выполнено сравнение с аналогичными зависимостями указанных характеристик для полукокса из угля 2Б. Установлено, что для получения полукокса из бурого угля 1Б с прочностью, сопоставимой с исходным углем, требуется давление в 1,5 раза выше, чем при использовании угля 2Б. Низкие значения водопоглощения и объема пор позволяют осуществлять транспортировку навалом в открытых вагонах без снижения качественных характеристик.

Получаемый полукокс также рекомендуется для использования в качестве углеродистого восстановителя в металлургических процессах производства ферросплавов, высокотемператур-

$$
-405-
$$


ного обжига руд и нерудных материалов, бездымного бытового топлива. Он может быть использован в качестве выскококалорийного топлива для вдувания в домны, а также в современных энергоустановках по получению пара с суперкритическими параметрами.

Предложена схема реализации непрерывного комбинированного производства полукокса и тепловой энергии. При этом часть вырабатываемого газового топлива используется для нагрева угля, а часть - сжигается в энергетических котлах.

\section{Список литературы / References}

[1] Галевский Г.В., Аникин А.Е., Руднева В.В., Галевский С.Г. Применение буроугольных полукоксов в металлургии: технологическая и экономическая оценка, Научнотехнические ведомости СПбПУ, 2016, 2, 114-123. [Galevsky G.V., Anikin A.E., Rudneva V.V., Galevsky S. G. Application of brown coal semi-cokes in metallurgy: technological and economic assessment, St. Petersburg polytechnic university journal of engineering science and technology, 2016, 2, 114-123 (in Russian)]

[2] Исламов С.Р. Частичная газификаџия угля. М.: Горное дело ООО «Киммерийский центр», 2017. 382 с. [Islamov S. R. Partial gasification of coal, Moscow, Gornoe Delo of LLC «Kimmeriysky center», 2017, 382 p. (in Russian)]

[3] Мизин В.Г., Серов Г.В. Углеродистые восстановители для ферросплавов, М.: Металлургия, 1976, 272 с. [Mizin V.G., Serov G. V. Carbon reducing agents for ferroalloys, Moscow, Metallurgiya, 1976, 272 p. (in Russian)]

[4] Евразийский патент 007798. МПК С10В 49/10 Способ слоевой газификаџии угля, С.Р. Исламов, С.Г. Степанов, А.Б. Морозов (РФ).- № 200801920; Заявлено 25.10.2005; Опубл. 27.02.2007, Бюл. ЕАПО 1. [Eurasian patent 007798. IPC C10B49/10 Method of layered coal gasification, S. R. Islamov, S. G. Stepanov, A. B. Morozov (RF). - No. 200801920; Declared 25.10.2005; Publ. 27.02.2007, EAPO Byul. 1 (in Russian)]

[5] Исламов С.Р., Степанов С.Г. Способ получения металлургического среднетемпературного кокса, Патент 2285715 РФ, 2006, Б.И. 29. [Islamov S. R., Stepanov S. G. A method for producing metallurgical medium-temperature coke, Patent 2285715 of the Russian Federation, 2006, B. I. 29 (in Russian)]

[6] Логинов Д. А., Черных А.П., Исламов С.Р. Экспериментальное исследование влияния давления на процесс полукоксования бурого угля, Химия твердого топлива, 2021, 2, 67-70. [Loginov D. A., Chernykh A. P., Islamov S. R. Experimental study of the influence of pressure on the process of semi-coking of brown coal, Solid Fuel Chemistry, 2021, 2, 67-70 (in Russian)]

[7] Ким В.А. Новые виды углеродистых восстановителей для выплавки технического кремния, Химия и металлургия комплексной переработки минерального сырья: материаль междунар. науч.-практ. конф., Караганда, 2015, 292-297. [Kim V. A. New types of carbon-based reducing agents for the smelting of technical silicon, Chemistry and metallurgy of complex processing of mineral raw materials: materials of the International Scientific and Practical Conference, Karaganda, 2015, 292-297 (in Russian)]

[8] Грязнов Н.С. Пиролиз углей в проиессе коксования, М.: Металлургия, 1983, 184 с. [Gryaznov N.S. Pyrolysis of coals in the process of coking, Moscow, Metallurgiya, 1983, 184 p. (in Russian)] 
[9] Исламов С.Р., Логинов Д.А., Черных А.П. Способ получения кускового карбонизаma, Патент 2725792 РФ, 2020, Б.И. 19. [Islamov S. R., Loginov D. A., Chernykh A.P. Method for obtaining lump carbonizate, Patent 2725792 of the Russian Federation, 2020, B. I. 19 (in Russian)] 